\title{
$\mathrm{ALC} \triangle \mathrm{NCE}$
}

\section{AS MÚLTIPLAS REPRESENTAÇÕES NO COTIDIANO: OS PAPÉIS DO DOCENTE DE PÓS-GRADUAÇÃO STRICTO SENSU EM ADMINISTRAÇÃO NO BRASIL}

MULTIPLE REPRESENTATIONS IN THE DAILY ROUTINE: THE ROLES OF STRICTO SENSU PROFESSORS OF POST-GRADUATE BUSINESS ADMINISTRATION COURSES IN BRAZIL

LAS MÚLTIPLES REPRESENTACIONES EN EL COTIDIANO: LOS PAPELES DEL DOCENTE DE POSGRADO STRICTO SENSU EN ADMINISTRACIÓN EN BRASIL

EDUARDO GUEDES VILLAR

Doutor

Universidade Federal do Paraná - Brasil

ORCID: 0000-0001-5005-4099 eduardogvillar@gmail.com

MARCOS VINÍCIUS PEREIRA CORREA

Doutor

Universidade Federal do Paraná - Brasil

ORCID: 0000-0002-8132-1097

marcoscorrea15@gmail.com

SILVANA ANITA WALTER

Doutora

Universidade Estadual do Oeste do Paraná - Brasil

ORCID: 0000-0003-1684-5465

silvanaanita.walter@gmail.com

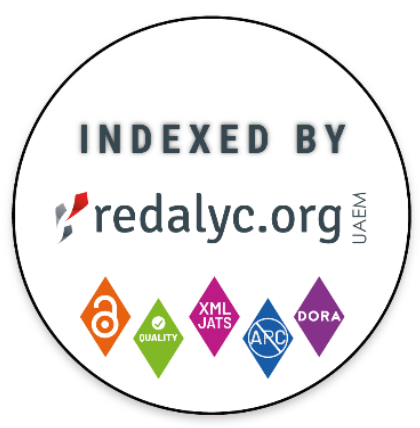

LCENÇA CC BY:

Artigo distribuído sob os termos Creative Commons, permite uso e distribuição irrestrita em qualquer meio desde que o autor credite a fonte original.
MARIANE LEMOS LOURENÇO

Doutora

Universidade Federal do Paraná - Brasil

ORCID: 0000-0003-2887-9232 marianellourenco@ufpr.br

Submetido em: 11/11/2018 Aprovado em: 05/08/2019

Doi: 10.14210.alcance.v26n3(set/dez).p334-347 


\section{RESUMO}

Neste trabalho, objetiva-se compreender como os papéis sociais são tipificados pelos docentes dos cursos de pósgraduação stricto sensu em Administração no Brasil. Realizou-se uma pesquisa de cunho qualitativo, adotando-se um estudo de casos múltiplos e a realização de 29 entrevistas com professores de 27 programas. A tipificação de papéis acontece quando 0 ator, como ser coletivo, atua em um determinado contexto com conhecimentos comuns a uma determinada coletividade de atores. Como resultado, evidenciou-se que os docentes assumem uma multiplicidade de papéis nas instituições de ensino superior e programas de pós-graduação para desenvolverem suas atividades cotidianas, de maneira que representam não apenas papel de professor, mas de pesquisador, orientador, coordenador, entre outros. A partir disso, esses múltiplos papéis, ora complementares, ora dissonantes, fazem com que o docente tenha que lidar com as diferentes pressões institucionais de representá-los, o que faz com que o docente acabe reprimindo determinadas atividades ou postergue-as para períodos que seriam de lazer e descanso. A contribuição central deste estudo está em compreender os meandros da própria profissão docente e os desafios da produção do conhecimento científico no país, uma vez que, nesse nível de ensino, realiza-se a formação dos futuros professores e pesquisadores do ensino superior.

Palavras-chave: Papel social; Multiplicidade de papéis; Socialização.

\section{ABSTRACT}

This paper aims to understand how social roles are typified by professors of stricto sensu postgraduate courses in Business Administration in Brazil. A qualitative research was conducted, adopting a multiple case study with 29 interviews with teachers from 27 programs. Role typification occurs when the actor, as a collective being, acts in a certain context with knowledge common to a certain collective of actors. As a result, it was evidenced that teachers assume a multiplicity of roles in higher education institutions and graduate programs, when carrying out the daily activities. Thus, they play the role not only of teacher, but also of researcher, advisor, and coordinator, among others. These multiple roles, sometimes complementary, sometimes dissonant, force the teacher to deal with different institutional pressures to perform these roles, which causes the teacher to end up repressing certain activities, or postponing them until what should be their leisure periods. The main contribution of this study is to understand the intricacies of the teaching profession and the challenges of the production of scientific knowledge in the country, since, at this level of education, it is through this knowledge that future teachers and researchers of higher education are trained.

Keywords: Social role; Multiplicity of roles; Socialization.

\section{RESUMEN}

Este trabajo tiene como objetivo comprender cómo los roles sociales son tipificados por los profesores de los cursos de posgrado stricto sensu en Administración de Empresas en Brasil. Se realizó una investigación cualitativa, adoptando un estudio de caso múltiple y realizando 29 entrevistas con maestros de 27 programas. La tipificación de roles ocurre cuando el actor, como un ser colectivo, actúa en un determinado contexto con conocimiento común a cierto colectivo de actores. Como resultado, se evidenció que los docentes asumen una multiplicidad de roles en instituciones de educación superior y programas de posgrado para desarrollar sus actividades diarias, de modo que desempeñan no solo el rol de docentes, sino también de investigador, asesor, coordinador, entre otros. A partir de esto, estos roles múltiples, a veces complementarios, a veces disonantes, hacen que el maestro tenga que lidiar con las diferentes presiones institucionales para representarlos, lo que hace que el maestro termine reprimiendo ciertas actividades o posponiéndolas por períodos. Sería de ocio y descanso. La contribución central de este estudio es comprender las complejidades de la profesión docente en sí y los desafíos de la producción de conocimiento científico en el país, ya que, en este nivel de educación, se capacitan futuros docentes e investigadores en enseñanza superior.

Palabras clave: Papel social; Multiplicidad de papeles; Socialización. 


\section{INTRODUÇÃO}

O contexto e a estrutura dos cursos de pós-graduação stricto sensu no Brasil têm se modificado nos últimos anos a fim de atender as exigências de órgãos de fomento à pesquisa e às agências reguladoras. A principal justificativa para tal mudança advém de uma preocupação com a qualidade dos cursos e das pesquisas desenvolvidas, assentandose sobre um conjunto de exigências sobre as universidades e os cursos de pós-graduação, impactando diretamente sobre as atividades cotidianas desenvolvidas pelos docentes. Nos cursos de pós-graduação em Administração, tais questões também são passíveis destas transformações, o que possibilita refletir a respeito do impacto das novas exigências sobre os papéis representados pelos docentes. Bertero et al. (2013), ao provocarem uma reflexão sobre os desafios da área de Administração no Brasil, indicam este espaço como um sistema social, que pode ser didaticamente dividido em três facetas: a) conteúdo propriamente dito (teorias, abordagens, conceitos, ferramentas e instrumentos); b) relações sociais em que os atores individuais e coletivos estão imersos e; c) aparato institucional da ciência.

Nos estudos sobre a área de Administração no Brasil tem-se privilegiado a faceta de conteúdo, especificamente retratando a produção acadêmica na área (Machado-Da-Silva, Cunha \& Amboni, 1990; Bertero \& Keinert, 1994; Bertero et al., 2013b), ou uma parcela desta (Bertero, Vasconcelos \& Binder, 2003; Hocayen-Da-Silva, Rossoni \& Ferreira Jr., 2008; Fonseca, Porto \& Borges-Andrade, 2014; Peinado \& Graeml, 2014), ou seja, "o que" se produz, e não sobre "quem" produz. Em detrimento a este interesse sobre a produção científica, compreender o modo como o conhecimento é disseminado torna-se um importante elemento desse próprio corpo de conhecimento (Berger \& Luckmann, 2012). Desta forma, ressalta-se a relevância em se aprofundar o conhecimento sobre a atuação do ator que representa e realiza a mediação nessa disseminação. Nesse sentido, tais elementos possibilitam refletir sobre como a ação docente contribui para o desenvolvimento da área, principalmente no que se refere às novas dinâmicas de trabalho na pós-graduação oriundas das exigências das universidades, dos órgãos reguladores e das agências de pesquisa. Assim, tais exigências perpassam não apenas a necessidade de lecionar em sala de aula e desenvolver pesquisas, mas por meio das métricas e dos índices de qualidade com base na estratificação, os docentes são avaliados pelo impacto científico e social de sua produção científica, o que é central para o funcionamento de um programa de pós-graduação stricto sensu e a permanência de seu quadro docente (Villar, 2018; Correa \& Lourenço). Além disso, a competitividade e a pressão por publicações impactam diretamente no pleito realizado pelo docente frente aos órgãos de fomento à pesquisa. Como resultado, o papel docente não se restringe mais apenas ao ensino e à pesquisa, recebendo pressões a respeito da produtividade, atuação internacional, contribuição teórico-científica, uma vez que, ao encontrar-se inserido em um quadro institucional de uma universidade, desenvolve também atividades como: monitoria, produção de pareceres e relatórios internos, orientação de alunos, participação em bancas de avaliação, participação em congressos nacionais e internacionais, atividades administrativas e atividades de extensão. Logo, ser docente de pós-graduação stricto sensu está além de apenas estar em sala de aula ou desenvolvendo artigos científicos, pois ser docente está atrelado aos papéis de professor, pesquisador, administrador, orientador, entre outros, o que envolve uma tensão tanto no cotidiano, quanto no desenvolvimento da carreira ao longo do tempo devido a essa potencial multiplicidade de papéis.

Acredita-se que uma análise do papel do docente poderá trazer subsídios para o entendimento aprofundado do campo. Particularmente, nesta pesquisa interessa-se em explorar as relações sociais no nível individual, as quais contemplam a ação do docente como professores, pesquisadores, líderes de tema, áreas e associações, editores e conselheiros de periódicos e representantes de área (Bertero et al., 2013). Por sua vez, a multiplicidade de papéis assumidos pelos docentes vincula-se a um conjunto de interações que compõem o cotidiano em instituições de ensino, desdobrando-se em novas exigências e significados que delimitam a permanência destes na pós-graduação. Ao assumir tal multiplicidade de papéis do docente, questiona-se: como se desenvolve a atividade docente?

A partir desta questão, objetiva-se compreender como os papéis sociais são tipificados pelos docentes dos cursos de pós-graduação stricto sensu em Administração no Brasil. O docente, nesta perspectiva, é entendido como ator social, representante de um ou mais papéis. A tipificação de papéis acontece quando esse ator, como ser coletivo, atua em um determinado contexto com conhecimentos comuns a uma determinada coletividade de atores. Além disso, a representação dos diferentes papéis sociais assumidos pelos docentes está atrelada a uma dimensão normativa, oriunda dos aspectos institucionais e legais que envolvem quais e como tais papéis devem ser desempenhados (Correa \& Lourenço, 2016). Não apenas universidades, mas órgãos reguladores e de fomento à pesquisa são capazes de legitimar a atividade do docente, delimitando os espaços e as exigências pelos quais diferentes papéis são desempenhados (e.g. pesquisador, professor, administrador, orientador, entre outros). Tendo como base esse contexto de atuação profissional, realizou-se a identificação de condutas e padrões de ação comuns aos docentes, ou a um conjunto desses que caracterize o estabelecimento de papéis sociais, analisados com base na descrição das atividades, das condutas rotinas e dos valores. $\mathrm{O}$ arcabouço teórico que orienta a análise dos papéis sociais baseia-se nas discussões empreendidas por Berger e Luckmann (2012) e versam sobre os padrões de conduta, as formas de ação e seus tipos, a formação dos papéis sociais, a representação de papéis e a necessidade institucional de conduta. De maneira complementar, a análise 
também se fundamentou na perspectiva de papéis sociais proposta por Goffman (2011), uma vez que, para o autor, os papéis sociais envolvem representações tipificadas face a face e que orientam as ações dos atores sociais conforme 0 contexto em que se encontram.

Nesta pesquisa, ao abordar a totalidade da ação docente, amplia-se a visão do professor (Nicollini, 2003; Aktouf, 2005) ou pesquisador (Alcadipani, 2011; Freitas, 2011), ou gestor acadêmico (Ésther \& Melo, 2008), deixando-se espaço para uma interpretação dos múltiplos papéis e suas interconexões. Optou-se, neste trabalho, por um recorte dos cursos de mestrado acadêmico e doutorado em Administração recomendados pela CAPES, por ser esse núcleo o principal promotor do corpo de conhecimento na área no Brasil (Ikeda, Campomar \& Veludo-De-Oliveira, 2005; Dantas, 2005).

Organizou-se este artigo em cinco seções. Além desta introdução, apresenta-se, em uma segunda seção, a base teórico-empírica para realização da pesquisa, em que se abordam o conhecimento sobre papel social e as pesquisas anteriores sobre a ação docente no stricto sensu. Na terceira seção, descrevem-se os procedimentos metodológicos empregados na pesquisa. A quarta seção destina-se à apresentação dos resultados obtidos e à realização das análises. Por fim, na quinta seção, realizam-se as considerações finais, abordando os principais resultados obtidos para cada objetivo específico, a resposta encontrada para a pergunta de pesquisa e sugestões para futuras pesquisas.

\section{FUNDAMENTAÇÃO TEÓRICA}

O arcabouço teórico deste trabalho estrutura-se nos estudos sobre papéis sociais em organizações (Goffman, 2011; Berger \& Luckmann, 2012). Para tanto, definem-se papéis como funções sociais que os atores assumem para desempenhar dado conjunto de atividades em um determinado contexto social (Castells, 2002). Por meio do processo de socialização, o indivíduo assume diferentes papéis sociais, tornando-se autor e ator dos enredos no cotidiano social e organizacional, na medida em que visa transmitir uma imagem que estabeleça uma comunicação com os demais atores na interação face a face (Goffman, 2011; Berger \& Luckmann, 2012).

Por meio das interações sociais, os indivíduos constroem significados na busca pela manutenção do status quo da realidade organizacional, refletindo não só no modo como compartilham valores e crenças, mas também representam seus papéis (Smircich, 1984; Weick; 1995). Ademais, ressalta-se que papéis e atividades são categorias complementares e não difusas, uma vez que determinado papel social é composto por um conjunto de atividades que lhe são específicas e que organizam funções por estes assumidas no contexto social/organizacional. Ao reconhecer essa dinâmica social, torna-se possível ampliar a compreensão a respeito do cotidiano organizacional e do modo como indivíduos representam seus papéis na relação com o outro, uma vez que, por meio do gerenciamento das impressões, 0 ator social pode resguardar ou trazer à tona determinados comportamentos e ações (Goffman, 2011).

A realidade não é independente da interpretação dos sujeitos, uma vez que se constitui por intermédio das interações sociais e dos significados compartilhados que moldam e sustentam a ação humana (Marsh \& Furlong, 2002; Berger \& Luckmann, 2012). Por meio deste debate, torna-se possível desvelar os elementos que compõem a dinâmica do cotidiano organizacional, uma vez que os indivíduos compartilham esquemas interpretativos e atribuem significados às ações por meio das interações sociais (Smircich, 1983). Estes significados são produzidos pelos indivíduos no exercício de representação de seus papéis sociais, com base na identificação destes com a organização (Miscenko \& Day, 2015; Brown, 2019). Nesse sentido, ao representar um conjunto de papéis sociais, os indivíduos constituem suas identidades em um processo de identificação com os próprios papéis representados, do mesmo modo com espaço organizacional em que estão inseridos.

Estudos empíricos recentes como de Lourenço, Dario e Rogge (2017) exemplificam essa premissa, ao destacarem por meio de pesquisa de história de vida, que o processo de identificação dos indivíduos com a organização pode ser impactado por jogos de poder. Já o estudo de Mathias e Willians (2014) demonstra que, dependendo da forma como determinados papéis sociais são representados, as decisões e o modo como os empreendedores buscam novos empreendimentos podem ser alterados. Em outro estudo, Bristow, Robinson e Ratle (2017) investigaram como acadêmicos da área de negócios resistiam ou consentiam as pressões e exigências nas universidades que estavam inseridos e, como resultado, os autores concluíram que o processo de construção de identidade de professores acadêmicos é permeado por uma tensão que pode impactar não apenas nos valores do indivíduo, mas na maneira como eles representam seu papel de pesquisador. Por fim, Bresnen et al. (2018) demonstram que os gestores assumem diferentes papéis ao trabalharem com diferentes grupos na organização, o que representa certo hibridismo de papéis, conforme as tarefas assumidas. Em suma, estes estudos contribuem no entendimento de que representação dos papéis em qualquer contexto organizacional está ancorada sempre na interação com o outro, por isso é situada e dinâmica.

Partindo-se desses elementos, a representação dos papéis sociais na organização envolve um processo de negociação de sentidos e significados a respeito da identidade dos indivíduos (Goffman, 2011). 0 ato de compartilhar 
informações e estabelecer interpretações comuns entre os membros organizacionais estrutura um palco social, no qual os atores organizacionais se apropriam, definem regras, compartilham experiências e buscam, em certa medida, sustentar um cotidiano organizacional coeso (Smircich, 1983; Goffman, 2011). Assim, os atores organizacionais, ao se apropriarem da realidade em que se encontram inseridos, a tornam significativa, em um movimento para si e para o outro, por intermédio das representações sociais que assumem.

A realidade social se estrutura e se mantém por meio dos processos de socialização primária e secundária. Conforme destacam Berger e Luckmann (2012), enquanto a socialização primária vincula-se às interações iniciais do indivíduo no contexto familiar, tornando-o um membro da sociedade, a socialização secundária se destaca como etapa conseguinte, em que o indivíduo passa a vivenciar outras instituições sociais, de forma a ressignificar o conjunto de significados apreendidos previamente. Com base nesses processos, torna-se possível compreender a dinâmica social que compõe dada realidade, principalmente quando se discute o mundo do trabalho. Nesse sentido, as organizações tornaram-se palco principal pelo qual os indivíduos representam determinados papéis, uma vez que o trabalho ganhou centralidade na vida cotidiana, sendo que o conjunto de atividades específicas que compõem os papéis é delineado de acordo com a divisão do trabalho existente (Berger \& Luckmann, 2012).

Os indivíduos no contexto das organizações, ao assumirem e representarem determinados papéis, buscam adequar seus comportamentos a partir das necessidades pessoais e da organização por meio dos processos de interação (Goffman, 2011). Ressalta-se, no entanto, que há um elemento de recursividade entre os indivíduos e as estruturas sociais, pois os indivíduos, ao mesmo tempo em que constituem tais estruturas, são por ela constituídas (Berger \& Luckmann, 2012). Com isso, a socialização no contexto das organizações não é estática, mas se reconstrói ao longo do tempo por meio dos enredos organizacionais que sustentam a ação e a representação dos papéis.

Por meio de um acervo de conhecimento compartilhado entre os atores ocorre a tipificação dos papéis sociais, de modo que para o ator social representar dado papel (professor, administrador, engenheiro, entre outros) necessita apresentar habilidades, conhecimento e apropriar-se de uma linguagem específica delimitada a dado contexto. Diante disso, os papéis de determinados profissionais nas organizações são definidos, uma vez que se estabelecem quais são as atividades e as ações necessárias para o desenvolvimento de determinado papel e quais são os atores que podem representar tais papéis (Berger \& Luckmann, 2012). Nesse sentido, com base em Goffman (2011), um ator social para representar, por exemplo, o papel de docente, necessita de uma formação e qualificações específicas que legitimem sua representação, de modo que nas interações cotidianas, esse ator se utiliza de uma linguagem e interage perante outros atores (professores, alunos, coordenação) a partir de um gerenciamento das impressões na interação, seja em sala de aula, reuniões de departamento, laboratórios e palcos sociais. São por estas razões que a perspectiva goffmaniana orienta um olhar para realidade social a partir de seu tecido social composto por interações face a face entre os atores organizacionais, ou seja, um conjunto de papéis que perpassam tanto uma estrutura formal de cargos, quando estruturas informais de interação.

O gerenciamento das impressões reflete o modo como os indivíduos se comportam no ator de representar dado papel, ou seja, essa representação do ator orienta-se em demonstrar ou não determinadas ações e atitudes na relação com o outro (Goffman, 2011). Com isso, as interações cotidianas são delimitadas pela definição da situação em que as ações dos atores se interligam no desempenho das atividades diárias. Por exemplo, no contexto de uma sala da aula, a relação professor e aluno é circunscrita por uma definição da situação, ou seja, o aluno aprender e o professor educar, fomentar debates.

Por meio de uma metáfora dramatúrgica, a abordagem da interação face a face proposta por Goffman (2011) orienta-se por uma análise resguardada ao próprio ato das interações sociais que tecem os enredos e as experiências entre atores. Assim, um ator, ao interagir com os demais, constitui um mundo social particular, e que de certa maneira passa a ser concreta para estes indivíduos. Conforme ressaltam Berger e Luckmann (2012), os papéis representam determinada ordem institucional, de modo que representar exige reconhecer e interagir com outros atores e seus papéis, desdobrando-se na totalidade de uma instituição. Logo, conforme os autores, uma instituição só se torna real a partir dessa pluralidade de papéis representados por diferentes atores, e que os papéis possibilitam a existência das instituições. Como exemplo, os papéis de professor, de aluno, de servidor compõem a instituição Universidade e o seu cotidiano, e como instituição é ela que possibilita que esses papéis se institucionalizem.

Diante dessas questões apresentadas, torna-se possível discutir os papéis sociais dos docentes de PósGraduação stricto sensu em Administração no Brasil. Conforme destaca Freitas (2007), a carreira acadêmica é composta por um conjunto de atividades, seja de pesquisa, ensino e extensão, e que conduz o docente a desenvolver os papéis de professor, pesquisador, gestor, entre outros, ao mesmo tempo, de modo que tais papéis nem sempre são passíveis de complementaridade. Para Bastos (2007), a dimensão do fazer acadêmico não é objeto de reflexões do próprio professor, de modo que o "ofício acadêmico", ou seja, sua atividade e o seu fazer cotidiano apresentam uma complexidade que 
conduz a pensar sobre o seu trabalho nas instituições de ensino. Nesse sentido, a profissão acadêmica segmenta-se em diferentes atuações, cada qual com suas exigências e seus significados específicos. Segundo o autor, ensino, pesquisa, extensão e gestão exigem diferentes competências por parte do docente, o que de certa forma, ao assumir esses diferentes papéis, pode ocasionar conflitos, desdobrando-se em estresse e sofrimento. Freitas (2007) discute que a profissão docente, assim como outras, também é composta por regras e exigências, mas que o docente tem liberdade e autonomia em suas atividades cotidianas, porém tal questão não significa que sua carga de trabalho não seja também intensa. Essa questão, segundo a autora, reflete-se em um excesso de trabalho e mudanças nas práticas de ensino e pesquisa, de modo que o docente deve ao mesmo tempo desenvolver suas aulas, pesquisas, publicar, avaliar trabalhos, participar de comissões, participar de congressos, solicitar financiamento de projetos, coordenar cursos, entre outros. Diante disso, essa exigência faz com que tais papéis sejam conflitantes e torna-se um paradoxo, uma atividade que ao mesmo tempo proporciona prazer e sofrimento (Bastos, 2007).

Os docentes, ao assumirem diferentes papéis, devido ao grau de exigência e dedicação, fazem com que o tempo que gostariam de dedicar à pesquisa, por exemplo, seja reduzido, uma vez que o docente se vê obrigado a desempenhar atividades administrativas, avaliar trabalhos de colegas, participar de comissões, entre outros (Melo \& Serva, 2012). Com isso, 0 ato de representar essa gama de papéis e atividades faz com que o docente dedique uma carga horária de trabalho, e que não apenas se delimita ao espaço das universidades, mas acaba por adentrar a outras instâncias da vida social.

Com base na discussão a respeito dos papéis em organizações, na próxima seção é apresentado o delineamento metodológico da pesquisa.

\section{DELINEAMENTO METODOLÓGICO}

Desenvolveu-se esta pesquisa com o objetivo de compreender os papéis sociais que são tipificados pelos docentes dos cursos de pós-graduação stricto sensu em Administração no Brasil. Para isso, realizou-se uma pesquisa de abordagem qualitativa, de modo a entender o fenômeno em profundidade e aprofundar o conhecimento sobre sua ocorrência (Dezin \& Lincoln, 2006).

No que tange aos procedimentos, classifica-se como um estudo de caso múltiplo (Stake, 1995), pois foram estudados conjuntamente alguns casos para investigar um dado fenômeno. Esses casos foram escolhidos porque se acredita que seu estudo permite melhor compreensão, ou mesmo melhor teorização, de um conjunto ainda maior de casos (Stake, 1995). Após levantamento dos programas de pós-graduação stricto sensu em Administração do país, optouse por um recorte dos cursos de mestrado acadêmico e doutorado em Administração recomendados pela CAPES, por ser esse núcleo o principal promotor do corpo de conhecimento na área no Brasil (Ikeda et al., 2005). Nesse sentido, não se levaram em consideração, nesta pesquisa, os programas stricto sensu com mestrados profissionais, em virtude de possuírem foco na orientação profissional (Ikeda et al., 2005).

Foram 54 cursos/programas identificados, sendo que todos possuíam o mestrado acadêmico e 34 deles ofereciam o doutorado em Administração. De todos os programas, escolheram-se os professores das disciplinas de "Estratégia" por ser a disciplina de conteúdo da área de Administração mais comum entre os programas. Após identificados programas, disciplinas e professores, entrou-se em contato via correspondência eletrônica com todos eles. Dos 54 sujeitos considerados inicialmente, 29 professores de 27 programas aceitaram participar da pesquisa, o que acabou compondo o corpus de análise deste trabalho.

Conduziram-se, portanto, vinte e nove entrevistas em profundidade com docentes de vinte e sete programas de cursos de mestrado e doutorado de pós-graduação stricto sensu em Administração, conforme discriminado na Tabela 1 a seguir:

\section{Tabela 1}

Distribuição geográfica dos programas e sujeitos da pesquisa

\begin{tabular}{lcc}
\hline Região & Sujeitos & Programas stricto sensu \\
\hline Centro-Oeste e Distrito Federal & 1 & 1 \\
Nordeste & 4 & 4 \\
Sudeste & 13 & 12 \\
Sul & 11 & 10 \\
Total & $\mathbf{2 9}$ & $\mathbf{2 7}$ \\
\hline
\end{tabular}

Fonte: Elaborada pelos autores. 
Apesar da pesquisa contar com a seleção intencional dos casos pesquisados, buscou-se uma distribuição geográfica dos sujeitos da pesquisa de acordo com a própria distribuição dos programas de pós-graduação stricto sensu em Administração no país (e.g. Ikeda et al., 2005). As entrevistas foram realizadas entre maio e setembro de 2013 com base em um roteiro semiestruturado elaborado pelos autores. Como forma de validação do instrumento, realizou-se anteriormente uma entrevista "teste" para avaliar e ajustar o roteiro de entrevistas. Realizou-se a coleta por meio de entrevistas conforme a disponibilidade dos sujeitos da pesquisa, das quais treze foram realizadas presencialmente, cinco por telefone e onze por videoconferência. Gravaram-se as entrevistas na íntegra, com o auxílio de um gravador digital, do que resultou o total de trinta e duas horas e trinta e oito minutos de gravação, com duração média de uma hora e sete minutos cada entrevista.

Posteriormente, se fez a transcrição, na íntegra, das entrevistas, o que gerou um relatório de quatrocentos e setenta e duas páginas (formatação Times New Roman, tamanho 12, espaçamento simples). Para a análise, utilizou-se a técnica de análise de conteúdo temática, em que o pesquisador interpreta e codifica os dados em categorias de maneira sucessiva, buscando um nível de detalhamento que possibilite a análise e a teorização sobre o conjunto de dados. Utilizou-se um software de análise qualitativa (Atlas.ti v. 6) para operacionalizar a categorização na etapa de análise.

As categorias de análise foram compostas por elementos que pudessem caracterizar condutas ou padrões de ação dos entrevistados, analisados com base na descrição de suas atividades (condutas e rotinas), assim como normas, valores e emoções. As categorias definidas a priori foram constituídas a partir da revisão da literatura, tendo como referência autores com Berger e Luckmann (2012) e Goffman (2011), que versam sobre a dimensão social da constituição e da representação dos papéis sociais nas organizações. Dessa forma, estas categorias foram as seguintes: Papéis Assumidos pelos Professores; Corpo de Conhecimento; Escolhas Pedagógicas no Ensino; Escolhas Metodológicas na Pesquisa; e Construção do Conhecimento. Além disso, a partir de um processo indutivo, novas categorias emergiram dos dados em um processo analítico a posteriori, categorias como: Conduta em Sala de Aula, Representação dos papéis perante ao aluno, Rotinas da Atividade Docente, Aspectos Afetivos do Sujeito com a profissão, Valores Relacionados ao Papel Social, Papéis Concorrentes e Papéis Complementares. Dessa forma, esse processo de codificação permitiu um diálogo constante entre a teoria e os dados, de maneira a evidenciar novos elementos que possibilitassem contribuir com a compreensão do fenômeno estudado e com o processo de teorização.

A análise de papéis, no entendimento de Berger e Luckmann (2012), pode ser realizada de maneira conjunta (indivíduo e coletividade) somente se indagar sobre os modos pelos quais o indivíduo, em sua atividade social total, se relaciona com a coletividade em questão. Assim, embora tenham sido realizadas entrevistas individuais em profundidade com os docentes, um exame conjunto desses indivíduos e de suas relações possibilitou a análise de papéis sob a perspectiva (nível de análise) da coletividade (ver Villar, 2018).

\section{ANÁLISE E INTERPRETAÇÃO DOS RESULTADOS}

Nesta seção, apresenta-se a análise das representações assumidas pelos entrevistados, por meio da identificação das condutas objetivados por estes. Na análise do papel do professor ao ministrar uma disciplina nos programas stricto sensu em Administração, analisaram-se a postura do professor em sala, o seu relacionamento com alunos e a sua forma de cobrança. A partir de tais questões, torna-se possivel compreender as nuances que alicerçam 0 cotidiano e que são significativas para estes atores com base nos casos analisados.

O cotidiano de um professor de pós-graduação stricto sensu envolve representar diferentes papéis, dentre eles se destaca o papel de professor. Ao representar este papel, o docente se posiciona perante um lugar, uma plateia e audiência específica (Goffman, 2011). O professor não tece um enredo em sala de aula de maneira isolada, mas reconhece seu espaço, interage e exerce a ação e a representação de seu papel perante seus alunos. Nesse sentido, 0 docente assume o papel previamente estabelecido e legitimado no social, porém sua representação torna-se única e abriga significados e dinâmicas específicas no contexto de sala de aula.

Diante dessas questões, em relação às posturas dos professores em sala, evidencia-se que a dinâmica envolve dimensões formais e informais de interação. $O$ aspecto formal da representação do papel de professor pode ser destacado, por exemplo, na fala do entrevistado 1, em que afirma que "Eu sou professor formal, cumpro os horários e dou aula. Raramente na pós-graduação eu tenho seminário. [...] raramente tem". Todavia, há outros docentes que representam o seu papel de modo que o aluno se torna ator central na dinâmica em sala de aula: "Na aula 0 aluno é tempo todo protagonista, eu sou acessório" (Entrevistado 15).

Evidencia-se a partir da fala dos entrevistados a existência de duas representações bem definidas em relação à postura do professor em sala de aula: a de centralizador e a de facilitador. Como centralizador, o professor assume uma conduta centrada nele mesmo. Nesta extremidade aulas são ministradas de maneira expositiva, sendo que 0 
conhecimento é transmitido em um sentido único (professor-aluno) e com pouca interação entre os alunos. Na outra extremidade, 0 professor como facilitador incentiva a interação entre os alunos, promove a disseminação do conhecimento em múltiplos sentidos (aluno-aluno, professor-aluno e aluno-professor) e as aulas são interativas por meio de discussões. Entretanto, verificou-se que os sujeitos entrevistados, em sua maioria, não se situam nestas extremidades, mas ao longo de um continuum nestas representações, conforme exemplificado na fala ilustrativa do Entrevistado 20:

\begin{abstract}
Acabo mudando minha atuação ao longo da disciplina. Quando eu estou dando aula, eu procuro ter uma postura de professor mesmo, no sentido de estar conduzindo a discussão, provocando, perguntando, usando o quadro negro, discutindo, apresentando, relacionando os conceitos. [...]. E existe o momento que eu tenho a postura de alguém que está observando e avaliando o seminário. $\mathrm{Na}$ apresentação dos alunos eu fico sentado, acompanhando, observando, por vezes, faço uma pergunta ou um esclarecimento, mas naquele momento o protagonista é o aluno (Entrevistado 20).
\end{abstract}

Neste sentido, entre as extremidades, apresentam-se inúmeras possibilidades de representações e condutas, conforme destacado pelo Entrevistado 19: "A gente tem vários perfis de professor [...]". Nota-se, ainda, conforme destacado na fala do Entrevistado 20, que o professor pode mudar sua postura de acordo com a necessidade pedagógica em sala. Pode, portanto, assumir uma postura mais centralizadora em uma parte da aula e mais facilitadora em outra. Contudo, na análise geral das entrevistas, verificou-se que, no nível de ensino de pós-graduação stricto sensu em Administração, os sujeitos pesquisados tendem a assumir uma postura mais próxima da extremidade "Facilitador". Estas falas aproximam-se dos resultados do estudo de Bristow, Robinson e Ratle (2017), em que conforme as exigências nas dinâmicas da interação social, os atores no processo de representação dos papéis sociais podem resistir ou aquiescer perante as novas dinâmicas de interação nas organizações.

Com base nessas questões, destaca-se que a postura do professor em sala de aula reflete uma dinâmica própria do cotidiano nos cursos de pós-graduação, em que revela que há um processo de construção de significados a respeito do que é e como representar o papel de professor em sala de aula. Tal questão reflete-se no gerenciamento de impressões que, de maneira específica, exprimem um modo de comunicar-se na relação face a face com 0 aluno (Goffman, 2011). Assim, a análise da conduta dos professores entrevistados no relacionamento com os alunos possibilita destacar que as condutas dos professores no relacionamento com seus alunos variam do aspecto formal até o informal, conforme trechos destacados a seguir:

A minha postura é essa: aqui dentro eu sou professor, e tenho um papel que eu vou cumprir esse papel. Aqui dentro eu não sou o amiguinho, eu não vou contar piada, eu tenho um papel claro, e eu cumpro meu papel [...]. Então é uma postura muito clara, de saber que eu sou o professor e estou aqui com um propósito de trabalhar (Entrevistado 23).

Eu brinco muito com eles, eu levo muito um tom de brincadeira, às vezes eu consigo ver, de uma forma até meio lúdica, "desculpa, mas essa sua apresentação aí tá muito ruim", fazer com que eles entendam, aceitem, mas sem conflitos, eu procuro evitar os conflitos (Entrevistado 18).

Percebe-se nos excertos apresentados, que a execução objetiva de um papel sofre influências dos papéis complementares da instituição em que este se insere (Berger \& Luckmann, 2012). Verifica-se que relacionamento dos professores entrevistados com seus alunos varia do aspecto formal até o informal, havendo, contudo, diversas possibilidades diferentes de interação professor-aluno entre esses dois tipos. Essa análise faz-se relevante, pois a execução objetiva de um papel sofre influências dos papéis complementares da instituição em que este se insere (Berger \& Luckmann, 2012). Além disso, essa mudança na dinâmica dos papéis complementares está vinculada ao processo de identificação dos professores para com suas tarefas e para com os grupos que fazem parte, o que impacta diretamente na representação de seus papéis, visto que é um processo relacional (Miscenko \& Day, 2016).

Verificou-se a partir das falas dos entrevistados que o professor, ao adotar uma postura mais formal, tende a manter um distanciamento maior do aluno, estabelecendo um relacionamento restrito ao ambiente acadêmico, com diálogo circunscrito aos assuntos da disciplina, e não tolera informalidades no tratamento dispensado a ele. 0 professor formal, pelos relatos obtidos, possui preferência pela avaliação do aluno por meio de provas; sua aula tende a ser mais expositiva, e sua postura, mais centralizadora. De certa forma, o professor de conduta informal, como pôde ser percebido nos relatos dos sujeitos da pesquisa, tende a estabelecer uma relação horizontal com o aluno, um relacionamento aberto a ambientes fora da universidade; divide suas particularidades com os alunos; se interessa pelas peculiaridades dos alunos; e promove um ambiente agradável em sala. Esse tipo de professor costuma adotar uma postura de facilitador, 
empregar seminários como técnica de ensino e fomentar a discussão aluno-aluno em sala.

No que se refere à forma e à intensidade da cobrança dos professores em sala, percebeu-se uma similaridade entre os professores. Os professores dos programas stricto sensu em Administração adotam um nível de cobrança que consideram elevado em suas aulas. Para tanto, destacam-se alguns trechos das falas dos entrevistados quando questionados sobre o nível de cobrança em suas aulas: "[Cobro] com bastante rigor,..." (Entrevistado 7), "Eu sou muito chato [...] eu cobro,..." (Entrevistado 17), "Sou muito rígido em termos de cobrança do que eu espero dos alunos" (Entrevistado 21), "Eu sou bem rigoroso [...] Eu cobro tudo: Cobro falta, presença, cobro participação, eu cobro um trabalho bem feito [...]" (Entrevistado 23).

A cobrança principal incide sobre a participação do aluno em sala e sobre sua interação com a disciplina. Os professores entrevistados justificam a cobrança pela curta duração das disciplinas. Para poderem desenvolver com a profundidade necessária todo o conteúdo da disciplina, cobram intensamente dos alunos. Além disso, identificou-se, também, uma cobrança quanto aos elementos formais de avaliação (provas, trabalhos e resumos). Dessa forma, percebe-se que essa exigência por parte do professor visa legitimar seu papel, demonstrando um sentido de diferenciação para com o aluno, estabelecendo dessa forma os limites entre o palco em que se posiciona perante seus alunos, sua plateia. Por sua vez, essa questão reflete quem orienta a definição da situação (Goffman, 2011), nesse caso, o professor.

No que tange às rotinas de atividades que orientam o desempenho dos papéis, analisaram-se a gestão do tempo, a carga horária, o regime de horário e a postura dos entrevistados diante de suas atividades que compõem seu cotidiano. Os principais resultados encontrados revelam, por meio da análise das rotinas dos sujeitos da pesquisa, que o docente assume uma multiplicidade de papéis, não apenas de professor, mas de pesquisador, orientador, coordenador, entre outros, e que, de certo modo, faz com que o docente se sinta sobrecarregado:

É uma rotina pesada, mas faz parte do trabalho do professor. Não sou daquele tipo que fala: 'Ah, coitado de mim, eu tenho tanto serviço pra fazer.' Eu sou professor por escolha, eu era profissional de mercado, [...] mas resolvi sair do mercado e ficar só na área acadêmica, porque eu achava que eu estava ganhando mais na área acadêmica, eu gosto muito dessa coisa de estudar, você aprender coisa nova" (Entrevistado 4).

São três grandes atividades: trabalho, trabalho e trabalho. Eu me levanto normalmente às seis horas da manhã, e me deito à meia-noite, essa é a rotina. $E$ da meia-noite às seis [horas] eu tenho o mau hábito de dormir. Mas das seis à meia-noite, eu trabalho na Universidade" (Entrevistado 8).

Nas rotinas dos entrevistados, não se identificou uma conduta estabelecida referente a um padrão de ação para a gestão de horários. Exemplifica-se esse resultado com as falas conflitantes dos entrevistados 12 e 22 . Um deles aplica um modelo bastante rígido de divisão do tempo para cumprir todas as suas atividades, enquanto outro deixa acumular atividades para o final de semana. Assim, quanto à postura diante da rotina do docente que atua em programas stricto sensu (e.g. professor, pesquisador, orientador, entre outros), verificou-se um padrão de conduta na dedicação deles às suas atividades. $\mathrm{Na}$ análise do regime de horas, percebeu-se que a flexibilidade de horários da profissão consiste em um atrativo. Salienta-se que a flexibilidade é relativa, uma vez que os horários de aula são previamente estabelecidos e necessitam ser cumpridos. Contudo, as atividades de leitura, pesquisa, avaliação e correção não são restringidas pelo espaço. Logo, o entrevistado possui flexibilidade de fazê-las no momento e no local que preferir.

Como destacado por Freitas (2007), a profissão docente é composta por suas regras e exigências, e mesmo que exista certo grau de autonomia, a carga de trabalho assumida pelo docente não deixa de ser intensa. Por sua vez, na relação da carga horária desempenhada efetivamente em suas funções, os entrevistados evidenciaram a extrapolação dos limites do "contrato" de trabalho. Não obstante a maioria dos entrevistados tenha regime de 40 horas com dedicação exclusiva, o trabalho estende-se para além da jornada semanal, para os fins de semana e para o período de férias: "Não tem período de férias, eu raramente pego férias. Quando que eu me ausento... eu me ausento quando tem conferências, congressos, ocasiões acadêmicas de maneira geral" (Entrevistado 27).

Em uma análise conjunta do regime e da carga horária, verifica-se a flexibilidade de horários, exposta como um atrativo da profissão, o que também facilita a transferência das atividades profissionais para o ambiente doméstico; sendo usual, portanto, os entrevistados realizarem atividades profissionais além da carga horária estabelecida, fora do ambiente acadêmico e em dias e horários diversificados. Entretanto, ressalta-se aqui que, mesmo que os papéis desempenhados pelo docente sejam conflitantes por vezes, é possível perceber que ainda há elementos afetivos que orientam a sua profissão. Com isso, perguntou-se aos entrevistados sobre os aspectos afetivos da profissão, ou seja, o que os motiva a 
construir uma carreira acadêmica e a se dedicar a essa carreira. Nesse contexto, como uma das possibilidades da pesquisa qualitativa, ressaltam-se as expressões corporais do sentimento de alegria - sorriso, "brilho nos olhos" e a sensação de cumplicidade dos entrevistados - ao responderem a essa pergunta, sobre o que os motiva a construir uma carreira acadêmica e a ela se dedicar, transferindo veracidade para as respostas obtidas:

Eu gosto de ser professor, eu digo o seguinte: no dia que eu entrar pra começar um curso e não sentir um friozinho na barriga, eu acho que eu devo ser professor, no dia em que eu não conseguir sair de uma aula energizado, de alma leve, cheio de entusiasmo eu deixo de ser professor. Eu gosto muito de dar aula (Entrevistado 1).

Eu gosto dessa coisa de estar em sala de aula e de ensinar. Eu acho gratificante você poder contribuir na formação de outra pessoa. O que me mantém como professor é isso, e enquanto eu tiver essa motivação, eu continuo em sala de aula, a hora que eu perder essa motivação, eu saio (Entrevistado 4).

Conforme os significados e os afetos expressos pelos entrevistados, é possível evidenciar o aspecto prazer, no sentido de que o docente reforça o gosto pelo que faz, e essa questão constitui um dos elementos do papel do docente dos programas stricto sensu em Administração. Segundo Berger e Luckmann (2012), em virtude dos papéis que desempenha, o indivíduo não é introduzido somente no sentido cognoscitivo estreito do papel, mas no conhecimento de normas, valores e mesmo emoções correspondentes a esse papel. Ressalta-se que nenhum entrevistado destacou fatores econômicos, financeiros ou de status como motivadores para a realização de suas atividades. Os entrevistados $8,16,22,23$ e 25 destacaram a possibilidade de serem mais bem remunerados em outras funções. Todavia, a satisfação e a liberdade proporcionadas pela atividade desempenhada foram apontadas como reforçadores de suas escolhas em investir na carreira de docência.

$\mathrm{Na}$ análise do papel social do professor, verificaram-se, ainda, os valores e os significados constituídos ao ensinar em programas stricto sensu. Com isso, percebem-se valores e significados relacionados diretamente à conduta de professor-pesquisador, por exemplo: postura, foco, conteúdo e exemplo. Além desses, verificaram-se valores e significados relacionados ao ser humano, como simplicidade, flexibilidade, atenção, confiança, honestidade, amor e integridade, que são comuns a outros papéis que exercem fora do domínio profissional. Tais valores foram destacados pelos entrevistados como essenciais para o desempenho adequado de seus papéis: "Você tem que transmitir [o conteúdo] de uma forma simples para as pessoas, não tem esse [negócio] de ficar rebuscando o raciocínio, para que os outros que estão te ouvindo te acharem inteligente, isso é uma grande bobagem" (Entrevistado 4) e "Plágio é plágio, não interessa se é uma página ou só um verso. Quem comete plágio, principalmente frente a um orientador, [...] quebra um laço de confiança" (Entrevistado 18).

Destaca-se ainda que esses valores são compreendidos pelos entrevistados como pertencentes ao papel social do professor de stricto sensu. Além do conteúdo que será estudado em uma disciplina ou trabalhado em uma pesquisa, o docente internaliza a necessidade de transmitir valores aos seus alunos. A transmissão desses valores faz-se por meio de suas ações, de suas atitudes e de seu comportamento, ou seja, da própria representação de seu papel social.

Além dos papéis de professor e pesquisador analisados, identificou-se outra gama de papéis representados pelos sujeitos da pesquisa. Entre essas múltiplas representações, destacam-se: (a) orientação; (b) aulas em outros níveis de ensino (graduação, especialização); (c) editores de periódicos; (d) revisores de artigos de periódicos e congressos científicos; (e) avaliadores ad hoc (CAPES; CNPq); (f) organizadores de eventos científicos; (g) membros de banca de mestrado e doutorado; e (h) funções de ordem administrativa na Universidade. Desse modo, essa discussão aproximase dos resultados de outras pesquisas empíricas em organizações, em que essa multiplicidade de tarefas exige dos atores organizacionais um hibridismo na representação de seus papéis, conforme diferentes espaços ou grupos sociais (Bresnen et al., 2018).

A atividade acadêmica neste nível de ensino (stricto sensu) contempla uma série de atividades que acabam concorrendo com as atividades de ensino e pesquisa. As atividades de revisor de periódicos foram destacadas pelo Entrevistado 29 como uma demanda frequente: "Chega na época do [Evento Nacional da Área], eles te mandam artigo, [outro evento] te mandam artigo. E periodicamente, [...] cinco, seis vezes por ano, vem artigo de periódico para gente analisar".

Além das atividades de revisão, os entrevistados elencaram exercer funções administrativas em suas universidades. Essas funções correspondem a funções de pró-reitor, coordenador, membro de conselho, chefe de departamento ou membro de comissão acadêmica que os sujeitos da pesquisa exerciam no momento da coleta. Sobre 
estas funções administrativas, os entrevistados apresentaram as restrições que esse tipo de atividade gera para a representação dos papéis de professor e pesquisador:

Desses 25 anos [de carreira acadêmica], pelo menos uns 16 anos eu estive envolvido com a administração, quer seja como chefe de departamento, quer seja como coordenador no MBA, quer seja como coordenador de pós-graduação stricto sensu, quer seja como diretor da [Universidade Privada da Região]. E isso tem um preço muito alto, porque a administração dentro de uma Universidade penaliza o acadêmico (Entrevistado 1).

Essa carga de trabalho é uma carga grande, [...] ainda sou membro do colegiado de coordenação de programa. A gente vive tendo reuniões, vive resolvendo várias situações administrativas. Mas parto do princípio que é a função mesmo, é natural da carreira docente, do docente que trabalha no stricto sensu, ele tem que lidar com isso (Entrevistado 4).

O papel de editor de periódicos, avaliador de artigos de periódicos e congressos científicos e de avaliador junto aos órgãos federais (CNPq e CAPES) acaba consumindo tempo e dedicação do indivíduo, prejudicando, dessa forma, sua atuação como professor e pesquisador (Freitas, 2007; Bastos 2007). Nota-se que as atividades de editor e avaliador agregam as atividades do professor-pesquisador e que, em última instância, são voluntárias (não remuneradas), assim como a participação em bancas e as avaliações ad hoc para CAPES e CNPq. Contudo, essas atividades, embora sejam concorrentes com a atividade de pesquisa e ensino, legitimam o papel de professor-pesquisador no campo social em que atua. Assim, quanto mais envolvido o professor-pesquisador estiver com esses tipos de atividades, melhor será sua "avaliação" frente a seus pares. Esse acúmulo de múltiplos papéis pode gerar consequências negativas ao próprio indivíduo, em termos de pressão psíquica e da própria saúde, conforme destacado pelo Entrevistado 19: "A gente vai ficando doente, vai perdendo o sono, porque tem que orientar, tem que preparar a aula, e tu tens que publicar com qualidade, [...] daí tu perde sono, tu trabalha sábado e domingo".

Diante desses aspectos, percebe-se que há uma multiplicidade de papéis que tende a fragmentar o cotidiano dos docentes. Devido ao excesso de papéis que necessita exercer, entre eles, professor, pesquisador, orientador, editor, avaliador e gestor, esse indivíduo partilha sua vida e seu tempo entre esses papéis, o que dificulta o efetivo exercício de algumas atividades. 0 Entrevistado 10 ressaltou a dificuldade de evoluir em suas pesquisas, em virtude da concentração e da dedicação requeridas para a atividade:

Em uma instituição pública, a gente além do trabalho de docência, de pesquisa e de orientação, hoje tem uma série de relatos, uma série de pareceres, uma série de reuniões. Eu como coordenador de programa, que fui ano passado, por exemplo, eu cheguei, eu chegava a ter semanas com seis reuniões na semana. E aí, para o trabalho de docência, quando você já tem uma certa maturidade até ia bem, mas para o trabalho de pesquisa não vai bem. A pesquisa talvez, a pesquisa qualitativa principalmente, uma pesquisa de reflexão teórica conceitual, eu não consigo chegar às oito da noite em casa, muito bem, agora eu tenho duas horas, pois não é suficiente. Eu preciso ter períodos longos em que só faço a reflexão, eu não consigo ter o fio da meada que eu retome a cada dia por duas horas, isto é um elemento que atrapalha (Entrevistado 10).

Percebe-se que, devido às necessidades institucionais de conduta (Berger \& Luckmann, 2012), ou seja, ao que a universidade como instituição social demanda, o indivíduo necessita representar múltiplos papéis. Contudo, esses papéis concorrem internamente no indivíduo, que, por sua vez, em decorrência das necessidades institucionais de representá-las, passa a reprimir determinadas atividades ou postergá-las para períodos que seriam de descanso. 0 Entrevistado 17 indicou que esses podem concorrer quando há uma exigência significativa sobre um deles: "Muitos professores acabam tendo que por obrigação das universidades ter que ter uma carga de hora/aula muito alta e acaba prejudicando o trabalho principal dele que é pesquisar". O Entrevistado 9 também apontou essa concorrência entre papéis: "Tento ajustar de forma que eu consiga continuar fazendo minhas atividades, embora ultimamente estou tendo dificuldade em função da grande demanda de aula e de orientação". Identificou-se o alargamento do período de trabalho e do trabalho em período de férias como soluções encontradas pelos sujeitos desta pesquisa para a necessidade de representação de múltiplos papéis. Embora possam concorrer com as atividades de pesquisa e ensino, os outros papéis identificados nesta pesquisa legitimam o papel de professor-pesquisador no campo social em que atua. Diante desses aspectos, ser professor na pós-graduação stricto sensu envolve uma tensão no desenvolvimento da carreira ao longo do tempo, pois o professor se depara com um hibridismo de papéis, podendo ou resistir ou aquiescer perante as dinâmicas sociais presentes no ambiente de trabalho (Miscenko \& Day, 2016; Bristow, Robinson e Ratle, 2017; Bresnen et al., 2018). 
Por fim, percebe-se que o docente significa seu trabalho com base no seu envolvimento com os papéis que desempenha, pois quanto mais envolvido estiver com esses outros tipos de papéis, melhor será sua "avaliação" frente a seus pares e a universidade em que atua. Entretanto, a fragmentação do cotidiano do docente reflete-se sobre o campo de conhecimento, uma vez que 0 docente se desorienta frente aos múltiplos papéis e às exigências, deixando 0 real significado da pesquisa em segundo plano.

\section{CONCLUSÃO}

$\mathrm{Na}$ análise do papel dos docentes dos programas stricto sensu em Administração, identificou-se que as posturas assumidas variam desde o professor centralizador até o facilitador. No relacionamento com os alunos, a conduta dos professores entrevistados também se diversifica entre a formalidade e a informalidade. Verificou-se, ainda, no papel do professor, a necessidade de cobrança quanto à participação do aluno em sala e sua interação com a disciplina. Além disso, na análise das rotinas dos professores, evidenciaram-se a necessidade de gestão do tempo, a dedicação para exercer todas as atividades que compõem sua rotina e a flexibilidade no horário de trabalho.

Sobre os valores compreendidos pelos entrevistados, ressaltam-se a postura, a simplicidade, a flexibilidade, 0 exemplo, a atenção, o foco, o conteúdo, a confiança, o amor e a integridade como valores pertencentes ao papel social do professor de stricto sensu. Identificou-se, na análise dos valores, que o professor internaliza a necessidade de transmitir valores aos seus alunos por meio de suas próprias condutas, ou seja, da própria representação de seu papel social.

No que se concerne às crenças, aos valores, às motivações e às rotinas referentes ao papel do pesquisador, percebeu-se que essas são próximas das condutas do papel do professor, uma vez que, na maior parte do tempo, esses papéis são representados de maneira conjunta. A flexibilidade de horários para a realização de pesquisas e a liberdade para escolha dos assuntos a serem pesquisados foram identificadas como vantagens no exercício das atividades de pesquisa. Todavia, devido às características do trabalho de pesquisa, notou-se que os entrevistados se dedicam aos seus trabalhos de pesquisa em períodos fora do regime de horas preestabelecidas pela sua universidade.

Além dos papéis de professor e pesquisador, identificou-se outra gama de papéis representados pelos sujeitos da pesquisa. Esses múltiplos papéis, ao mesmo tempo em que dificultam o desempenho das atividades de professor e pesquisador em virtude do volume de trabalho, os legitimam, uma vez que, quanto maior o número de papéis assumidos, maior será seu reconhecimento no campo. Nesta pesquisa, verificou-se que cada papel compreende conhecimentos, condutas e rotinas específicos, de modo que exige uma dedicação do docente para representar cada papel, porém alguns papéis podem não ser passíveis de conformidade, gerando papéis concorrentes (Bastos, 2007; Goffman, 2011), o que de certa maneira pode gerar tensões (Bresnen et al., 2018) e, por vezes, descontentamento do docente.

Salienta-se que o estudo dos múltiplos papéis neste nível de ensino pode contribuir para compreender a própria profissão docente e a produção do conhecimento científico no país, uma vez que, nesse nível de ensino, realiza-se a formação dos futuros professores e pesquisadores do ensino superior (Ikeda et al., 2005). Além disso, os programas stricto sensu também são responsáveis pela maior parte da produção científica brasileira (Dantas, 2004). A partir do apresentado, conclui-se que a análise dos papéis dos profissionais de educação stricto sensu em Administração, objeto deste trabalho, permitiu um entendimento mais aproximado da realidade dessa área temática. Verifica-se, ainda, a contribuição da Sociologia do Conhecimento para a estruturação de um esquema analítico que inclua 0 ator social no processo de investigação da construção social do conhecimento em Administração.

Quanto às limitações da pesquisa, a representação do papel social ficou restrita à interpretação que os sujeitos da pesquisa fizeram de seus próprios papéis, podendo conter enganos, estimativas e supervalorizações dessas interpretações. Reforça-se, contudo, que a análise de múltiplos casos, a triangulação na coleta de informações, as categorizações sucessivas e estruturadas e a comparação dos resultados com a teoria na área foram empregadas neste trabalho com o intuito de minimizar tais ocorrências.

\section{REFERÊNCIAS}

Alcadipani, Rafael. (2011) Resistir ao produtivismo: uma ode à perturbação acadêmica. Cadernos EBAPE. BR, 9 (4), 1174-1178.

Bardin, L. (2010). Análise de Conteúdo. Lisboa: Edições 70. 
Bastos, A.V.B. (2007). Réplica: o ofício acadêmico: singular ou plural? Revista Organização e Sociedade, 14 (3), out./dez., 179-185.

Berger, P. L., \& Luckmann, T. A (2012). Construção Social da Realidade: tratado de sociologia do conhecimento. Rio de Janeiro: Vozes.

Bertero, C. O., Alcadipani, R., Cabral, S., Faria, A., \& Rossoni, L. (2013). Os desafios da produção de conhecimento em administração no Brasil. Cadernos EBAPE. BR, 11 (1), 181-196.

Bertero, C. O., \& Keinert, T. M. M. (1994). A evolução da análise organizacional no Brasil. Revista de administração de empresas, 34 (3), 81-90.

Bertero, C. O., Vasconcelos, F. C. de, \& Binder, M. P. (2003). Estratégia empresarial: a produção científica brasileira entre 1991 e 2002. Revista de administração de empresas, 43 (4), 48-62.

Bertero, C. O., Vasconcelos, F. C. de, Binder, M. P., \& Wood Jr., T. (2013). Produção científica brasileira em administração na década de 2000. Revista de administração de empresas, 53 (1) 12-20.

Bristow, A., Robinson, S., \& Ratle, O. (2017). Being an early-career CMS academic in the context of insecurity and 'excellence': The dialectics of resistance and compliance. Organization Studies, 38(9), 1185-1207.

Bresnen, M., Hodgson, D., Bailey, S., Hassard, J., \& Hyde, P. (2018). Hybrid managers, career narratives and identity work: a contextual analysis of UK healthcare organizations. Human Relations, 0018726718807280.

Brown, A. D. (2019). Identities in Organization Studies. Organization Studies, 40(1), 7-22.

Castells, M. (2002). A Era da Informação: o Poder da Identidade. São Paulo: Paz e Terra.

Correa, M. V. P., \& Lourenço, M. L. (2016). A constituição da identidade dos professores de pós-graduação stricto sensu em duas instituições de ensino superior: um estudo baseado nas relações de poder e papéis em organizações. Cadernos Ebape. BR, 14(4), 858-871.

Dantas, F. (2004). Responsabilidade social e pós-graduação no Brasil: idéias para (avali)ação. RBPG - Revista Brasileira de Pós-graduação, 1 (2), 141-159.

Denzin, Norman K., \& Lincoln, Yvonna S. (2006). O planejamento da pesquisa qualitativa: teorias e abordagens. Porto Alegre: Artmed.

Ésther, A. B., \& Melo, M. D. O. (2007). A construção da identidade gerencial dos gestores de alta administração de universidades federais em Minas Gerais: o caso dos reitores. Encontro Da Associação Nacional De PósGraduação E Pesquisa Em Administração, Anais... Rio de Janeiro, ANPAD.

Flores, J.G. (1994). Análisis de Datos Cualitativos. Barcelona: PPU.

Freitas, M. E. (2007). A carne e os ossos do ofício acadêmico. Revista Organização e Sociedade,14 (42), jul./set., 187191.

Freitas, M. E. De. (2011). O pesquisador hoje: entre o artesanato intelectual e a produção em série. Cadernos Ebape.BR, 9 (4), 1158-1163.

Goffman, E. (2011). A representação do eu na vida cotidiana. 19. ed. Petrópolis: RJ: Vozes..

Ikeda, A. A., Campomar, M. C., \& Veludo-De-Oliveira, T. M. (2005). A Pós-graduação em Administração no Brasil: definições e esclarecimentos. Gestão \& Planejamento-G\&P, 1 (12).

Lourenço, M. L.; Dario, V. C.; Rogge, J. F. N. (2017). A história de Nice: um caso de amor, idealização e identificação em organizações. Revista Alcance - Eletrônica, 24 (3). 
Machado-Da-Silva, C. L., Cunha, V. C., \& Amboni, N. (1990). Organizações: o estado da arte da produção acadêmica no Brasil. Encontro Anual Da Associação Nacional Dos Programas De Pós-Graduação Em Administração, Anais..., Rio de Janeiro, ANPAD.

Marsh, D., \& Furlong, P. (2002) A Skin not a Pullover: Ontology and Epistemology in Political Science. Theory and Methods in Political Science, SAGE.

Melo, D., \& Serva, M. (2012). A agenda do professor pesquisador em Administração: uma análise baseada na sociologia da ciência. II Colóquio Internacional de Epistemologia e Sociologia da Ciência da Administração, Anais.... Florianópolis, UFSC.

Miscenko, D., \& Day, D. V. (2016). Identity and identification at work. Organizational Psychology Review, 6(3), 215-247.

Nicolini, A. (2003). Educação em administração. Qual será o futuro das fábricas de administradores?. RAE-Revista de Administração de Empresas, 43 (2), 44-54.

Oliveira Fonseca, A. M., Porto, J. B., \& Borges-Andrade, J. E. (2015). Liderança: Um Retrato da Produção Científica Brasileira. RAC-Revista de Administração Contemporânea, 19 (3).

Peinado, J., \& Graeml, A. R. (2014). Pesquisa, Ensino e Prática de Gestão de Operações: Consonâncias e Divergências entre Três Mundos. RAC-Revista de Administração Contemporânea, 18 (5), $627-649$.

Rossoni, L., Hocayen-Da-Silva, A. J., \& Ferreira Jr., I. (2008). Aspectos estruturais da cooperação entre pesquisadores no campo de administração pública e gestão social: análise das redes entre instituições no Brasil. Revista de Administração Pública, 42 (6), 1041-1067.

Smircich, L. (1983). Concepts of culture and organizational analysis. Administrative science quarterly, 339-358.

Stake, Robert E. (1995) The art of case study research. London: Sage Publications.

Villar, E. G. As interações entre atores da pós-graduação stricto sensu em Administração: uma análise do indivíduo e da coletividade. Revista Gestão Universitária da América Latina - GUAL, 11 (2), 47-69, 2018.

Weick, K. E. (1995). Sensemaking in Organizations. Thousand Oaks, CA: Sage. 